\title{
Evaluation of in vivo biocompatibility of different devices for interventional closure of the patent ductus arteriosus in an animal model
}

\author{
M Sigler, S Handt, M-C Seghaye, G von Bernuth, R G Grabitz
}

\begin{abstract}
Objective-To evaluate the in vivo biocompatibility of three different devices following interventional closure of a patent ductus arteriosus (PDA) in an animal model.

Materials and methods-A medical grade stainless steel coil $(n=8)$, a nickel/titanium coil $(n=10)$, and a polyvinylalcohol foam plug knitted on a titanium wire frame $(n=11)$ were used for interventional closure of PDA in a neonatal lamb model. The PDA had been maintained by repetitive angioplasty. Between one and 278 days after implantation the animals were killed and the ductal block removed. In addition to standard histology and scanning electron microscopy, immunohistochemical staining for biocompatibility screening was also undertaken.

Results-Electron microscopy revealed the growth of a cellular layer in a cobblestone pattern on the implant surfaces with blood contact, which was completed as early as five weeks after implantation of all devices. Immunohistochemical staining of these superficial cells showed an endothelial cell phenotype. After initial thrombus formation causing occlusion of the PDA after implantation there was ingrowth of fibromuscular cells resembling smooth muscle cells. Transformation of thrombotic material was completed within six weeks in the polyvinylalcohol plug and around the nickel/titanium coil, and within six months after implantation of the stainless steel coil. An implant related foreign body reaction was seen in only one of the stainless steel coil specimens and in two of the nickel/titanium coil specimens.

Conclusion-After implantation, organisation of thrombotic material with ingrowth of fibromuscular cells was demonstrated in a material dependent time pattern. The time it took for endothelium to cover the implants was independent of the type of implant. Little or no inflammatory reaction of the surrounding tissue was seen nine months after implantation.

(Heart 2000;83:570-573)
\end{abstract}

Keywords: congenital heart disease; patent ductus arteriosus; catheter technique; biocompatibility

Porstmann $^{1}$ described the first transcatheter closure of a PDA in 1968. Since then, several devices have been developed and used in clinical practice..$^{23}$ In the meantime, interventional closure has become the treatment of choice for PDA after the neonatal age.

At present, all devices for interventional clo-

Department of Pediatric Cardiology, Aachen University of Technology,

Pauwelsstr.30, D-52057

Aachen, Germany

M Sigler

M C Seghaye

$G$ von Bernuth

R G Grabitz

\section{Interdisciplinary \\ Center of Clinical \\ Research on \\ Biomaterials, Aachen \\ University of \\ Technology, Germany \\ M Sigler \\ R G Grabitz}

Department of

Pathology, Aachen

University of

Technology, Germany

$S$ Handt

Correspondence to:

Dr Sigler

Accepted 13 January 2000 sure of the PDA are made from non-resorbable materials. After implantation these biomaterials are left in the body for life. Little attention, however, has been paid to the in vivo biocompatibility of these PDA implants. ${ }^{4}$

We therefore evaluated and compared tissue specimens from lambs following interventional closure of PDA with three devices currently in clinical use, focusing on three main points: (1) examination of the blood-implant interface as a possible source for intravascular thrombus formation; (2) determination of the mechanism of closure and the process of tissue organisation by histomorphological methods;

Table 1 Animal groups

\begin{tabular}{lrll}
\hline & & $\begin{array}{l}\text { Minimum diameter } \\
\text { of ductus arteriosus } \\
\text { at implantation } \\
(\mathrm{mm})\end{array}$ & $\begin{array}{l}\text { Mean (range) } \\
\text { implantation } \\
\text { time }\end{array}$ \\
Implant & $\begin{array}{l}\text { Number } \\
\text { of lambs }\end{array}$ \\
\hline PVA plug & 11 & $6.0(4.5-9.0)$ & $102(10-215)$ \\
Stst coil & 8 & $6.3(5.0-7.8)$ & $74(1-181)$ \\
NiTi coil & 10 & $7.0(6.0-8.0)$ & $106(7-278)$ \\
\hline
\end{tabular}

^Time interval between implantation and death; PVA, polyvinylalcohol; Stst, stainless steel; NiTi, nickel/titanium. and (3) evaluation of the implant related inflammatory reaction following implantation.

\section{Methods}

ANIMAL STUDIES

The animal experiments were conducted according to the guidelines of the German animal protection law and were approved by the state agency supervising animal experimenta-

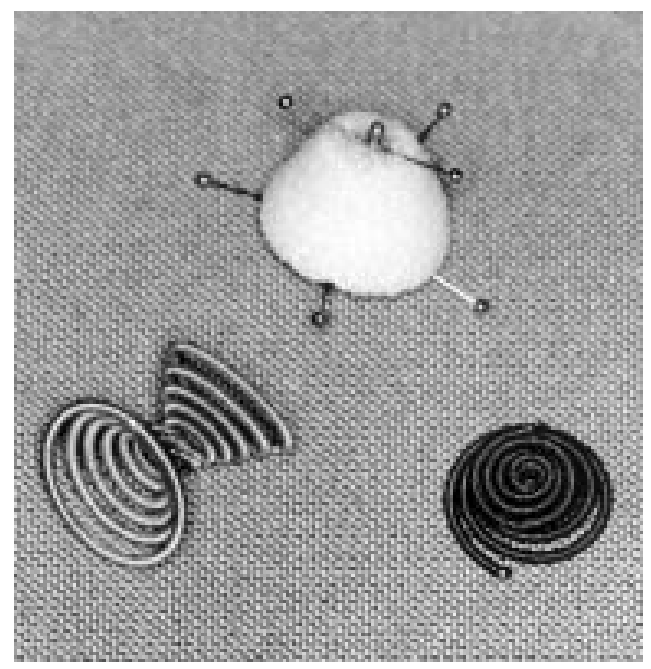

Figure 1 The implants. Top, foam polyvinylalcohol plug; bottom left, stainless steel coil; bottom right, nickel/titanium coil. 
Table 2 Details of animals, implants, implantation time and morphological findings

\begin{tabular}{|c|c|c|c|c|c|}
\hline Lamb & Implant & $\begin{array}{l}\text { Implantation time } \\
\text { days }\end{array}$ & Surface & Ingrowth & Inflammation \\
\hline 1 & PVA plug & 10 & Fibrin/cells & Thrombus & - \\
\hline 2 & PVA plug & 16 & Fibrin/cells & Thrombus/cells & - \\
\hline 3 & PVA plug & 42 & Cells & Cells & - \\
\hline 4 & PVA plug & 65 & Cells & Cells & - \\
\hline 5 & PVA plug & 109 & Cells & Cells & - \\
\hline 6 & PVA plug & 112 & Cells & Cells & - \\
\hline 7 & PVA plug & 117 & Cells & Cells & - \\
\hline 8 & PVA plug & 128 & Cells & Cells & - \\
\hline 9 & PVA plug & 131 & Cells & Cells & - \\
\hline 10 & PVA plug & 186 & Cells & Cells & - \\
\hline 11 & PVA plug & 215 & Cells & Cells & - \\
\hline 12 & Stst coil & 1 & Fibrin & Thrombus & - \\
\hline 13 & Stst coil & 13 & Fibrin/cells & Thrombus & - \\
\hline 14 & Stst coil & 52 & Cells & Thrombus & - \\
\hline 15 & Stst coil & 62 & Cells & Thrombus & - \\
\hline 16 & Stst coil & 80 & Cells & Thrombus & - \\
\hline 17 & Stst coil & 98 & Cells & Thrombus & - \\
\hline 18 & Stst coil & 107 & Cells & Thrombus & - \\
\hline 19 & Stst coil & 181 & Cells & Cells & $\mathrm{FBR}^{\star}$ \\
\hline 20 & NiTi coil & 7 & Fibrin & Thrombus & - \\
\hline 21 & NiTi coil & 32 & Cells & Cells & - \\
\hline 22 & NiTi coil & 48 & Cells & Cells & - \\
\hline 23 & NiTi coil & 58 & Cells & Cells & - \\
\hline 24 & NiTi coil & 70 & Cells & Cells & Unspecific \\
\hline 25 & NiTi coil & 89 & Cells & Cells & - \\
\hline 26 & NiTi coil & 111 & Cells & Cells & - \\
\hline 27 & NiTi coil & 154 & Cells & Cells & Unspecific \\
\hline 28 & NiTi coil & 216 & Cells & Cells & FBR \\
\hline 29 & NiTi coil & 278 & Cells & Cells & FBR \\
\hline
\end{tabular}

${ }^{\star} \mathrm{FBR}$, foreign body reaction.

tion. All interventions were performed as sterile procedures under general anaesthesia with halothane $(0.3-0.6 \%)$ and nitrous oxide. No antibiotics, antithrombotic agents, or any other medication were administered at any time. After intervals of between 1 and 278 days after implantation the lambs were killed with an overdose of barbiturate (table 1).

To develop the animal model of the PDA, the ductus arteriosus was dilated up to three times within the first 20 days of life in 29 neonatal lambs (morino mixed), using a paediatric valvuloplasty catheter (balloon diameter 6 or $8 \mathrm{~mm}$, length $20 \mathrm{~mm}$; Dr Osypka $\mathrm{GmbH}$, Grenzach, Germany).

\section{INTERVENTION AND DEVICES}

Implantation of devices was performed percutaneously via catheters introduced into the

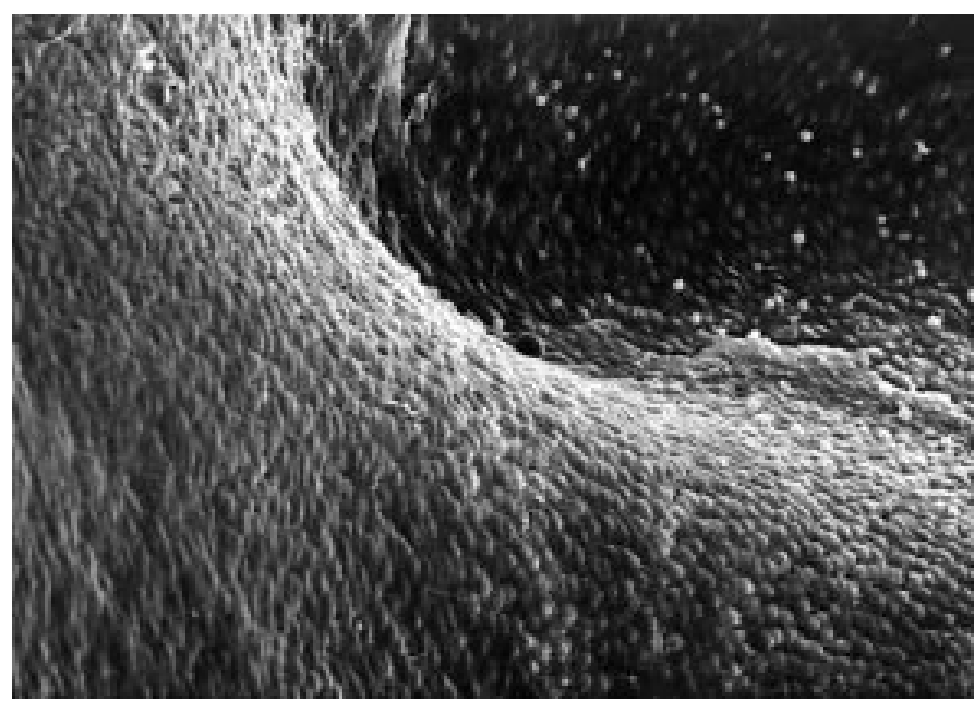

Figure 2 Cobblestone pattern of endothelial cells on the surface of the aortic orifice of a ductus arteriosus 112 days after interventional closure with a polyvinylalcohol plug (lamb 6). Electron microscopy $\times 600$. femoral artery and jugular vein $17-53$ days (mean 30 days) after the last dilatation. Patency of the ductus arteriosus was demonstrated by angiography in all animals at this time.

\section{Polyvinylalcohol plug}

This device consists of a conically shaped polyvinylalcohol foam plug (diameter 8-20 mm) mounted on a core pin (platinum-iridium alloy) where, at both ends, small legs (titanium nickel alloy) with titanium heads are anchored, to ensure safe fixation in the ductus (ID Medizintechnik, Gelnhausen, Germany) (fig 1).

\section{Stainless steel coil}

The stainless steel coil is shaped in a double cone from medical grade stainless steel (DIN 1.4310) with enhanced stiffness of the outer rings as a result of double helix configuration, mounted on a nickel/titanium core wire (pfm $\mathrm{GmbH}$, Cologne, Germany) (fig 1).

\section{Nickel/titanium coil}

The nickel/titanium coil is also double cone shaped but is made entirely from nickel/ titanium alloy with selectively enhanced stiffness through additionally incorporated core struts (pfm GmbH, Cologne, Germany) (fig 1).

\section{PREPARATION}

Immediately after death, the ductal block as well as parts of the ascending and descending aorta and pulmonary artery were removed. After flushing with $0.9 \%$ sodium chloride, the specimens were fixed in ethanol/methanol (50:50). The aortic portion of the ductal block was submitted for scanning electron microscopy and placed in glutaraldehyde (3\%).

The parts of the ductal blocks containing the devices were embedded in methylmethacrylate (Technovit 9100, Kulzer \& Co, Wehrheim, Germany), hardened, and subsequently sectioned into $0.8 \mathrm{~mm}$ width slices using a diamond cutter. These slices were further ground down to $30-80 \mu \mathrm{m}$ width. Staining was performed with toluidine blue.

The other portions of the ductal block and the connected great arteries were embedded in paraffin, serially sectioned crosswise, and stained for standard histology with haematoxylin and eosin, and elastica van Gieson. For immunohistochemical staining, binding of first antibodies was detected using horseradish peroxidase conjugated secondary antibodies. The sections were counterstained with haematoxylin.

\section{Results}

No evidence of thromboembolic events or recanalisation (once occlusion had been achieved) was found clinically in the 29 animals following implantation. No thrombi were found locally adjacent to the superficial cells at the site of the implant at necropsy in any of the animals.

CELLULAR COVERAGE OF IMPLANTS IN BLOOD CONTACT

A uniform morphological pattern of cellular coverage of the implants on the aortic and pul- 


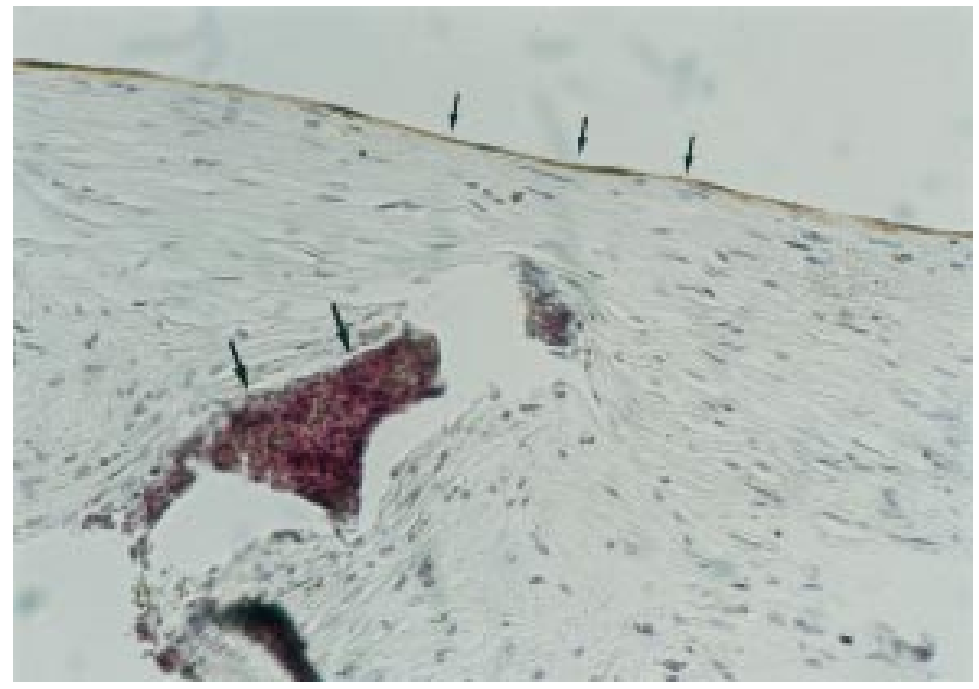

Figure 3 Positive immunohistochemical staining for von Willebrand factor in superficial endothelial cells (smaller arrows) covering the aortic orifice of a ductus arteriosus 117 days after implantation of a polyvinylalcohol plug. Larger arrows indicate foam material. $\times 800$

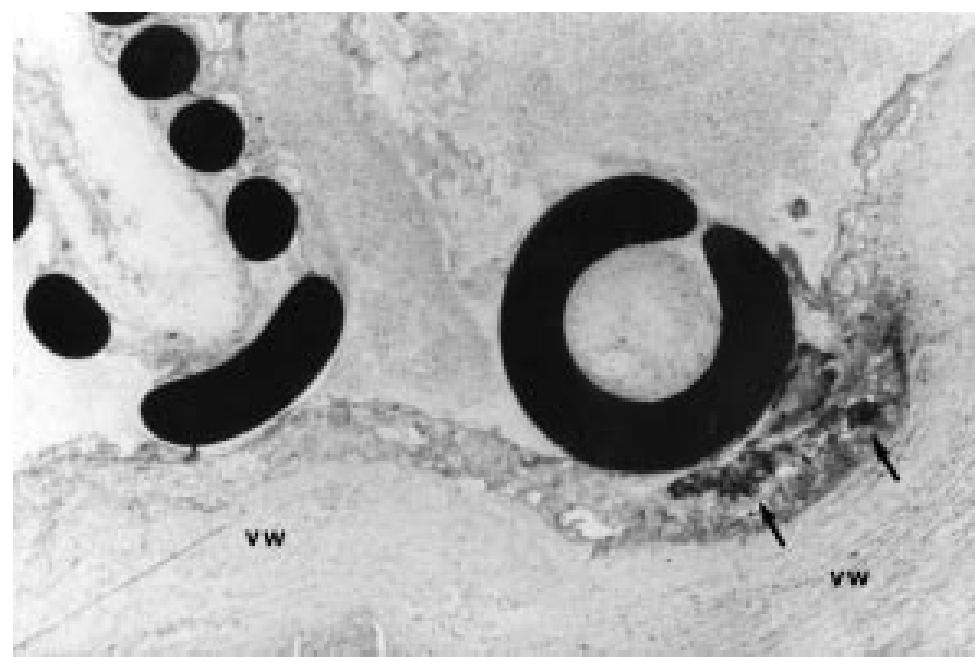

Figure 4 Central ductal portion filled with thrombotic material around coil loops in a lamb 107 days after stainless steel coil implantation. Methylmethacrylate embedded, ground section, toluidine blue stain. Black areas are the coil sections and the arrows indicate calcification. $V W$, vessel wall. $\times 200$.

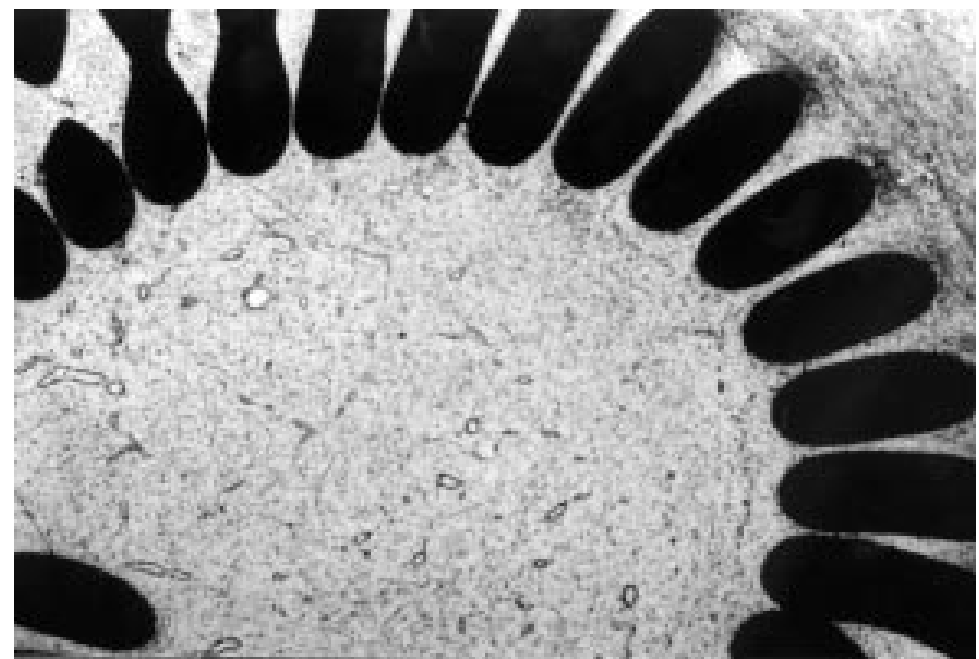

Figure 5 Central portion of an occluded ductus arteriosus in a lamb 32 days after nickel/titanium coil implantation, filled with fibromuscular cells. Methylmethacrylate embedded, ground section, toluidine blue stain. Black areas are the coil sections. $\times 200$. monary end of the ductus arteriosus was seen over a corresponding time course (table 2 ).

As demonstrated by electron microscopy the growth of cells was preceded by the formation of a fibrin net on the free surfaces of the implants. The earliest timepoint after implantation at which endothelial cells were observed adjacent to the surface of the fibrin net was 10 days (lamb 1) in our series. The cellular coverage appeared to be complete in implants with an implantation time (interval between implantation and death) of at least 32 days. All implants from animals with longer implantation times demonstrated coverage with cells showing a cobblestone pattern (fig 2 ) or a spindle shape pattern independent of implant type or implantation time.

Immunohistochemical staining of the superficial cells in conventionally embedded specimens from the polyvinylalcohol plug group were positive for von Willebrand factor, which identifies them as endothelial cells (fig 3).

\section{INGROWTH OF IMPLANTS}

In the earliest specimen of the nickel/titanium coil group (lamb 20, 7 days) and the polyvinylalcohol plug group (lamb 1, 10 days and lamb 2, 16 days), and in all but the longest running specimen of the stainless steel coil group (lamb 19, 181 days), thrombotic material filled the central portion of the ductus arteriosus lumen around the coil loops and among the foam material (fig 4). All other specimens showed occlusion of the lumen by cellular material with good vascularisation (fig 5 ).

In the newly formed intraluminal cells of the polyvinylalcohol plug specimen immunohistochemical staining was positive for smooth muscle actin, desmin (both indicative of muscle cells), and vimentin (indicative of mesenchymal origin). Although immunohistochemical staining could not be performed in the specimens from the two coil groups, cells appeared to be morphologically identical to those found in the plug specimen.

INFLAMMATORY REACTION

Independent of type of implant, lymphocytes, histiocytes, and a few polymorphonuclear neutrophils were detected in a loose distribution in thrombotic material occluding the ductus arteriosus before cellular organisation, consistent with thrombus remodelling.

No inflammatory reaction was detected in the polyvinylalcohol plug specimens following complete cellular organisation.

In the stainless steel coil group, histologic specimens from two animals showed signs of inflammation besides infiltrates caused by thrombus remodelling. Specimens from lamb 15 (62 days) demonstrated a local inflammatory infiltrate of polymorphonuclear cells in the media of the vascular wall without direct contact with the implant. In the specimens of lamb 19 (181 days) single giant cells were detected in the newly formed tissue around coil material, consistent with a foreign body reaction.

Two animals in the nickel/titanium coil group (lamb 24, 70 days; lamb 27, 154 days) 
demonstrated a loose and unspecific lymphohistiocytic infiltrate in the newly formed tissue. Histological signs of inflammation consistent with foreign body reaction were detected in the specimens from two animals (lamb 28 and lamb 29).

\section{Discussion}

Functional results following implantation of these devices in lambs are presented and discussed elsewhere. ${ }^{67}$ In addition to evaluating the functional properties and handling of these devices, an animal model allows screening for in vivo biocompatibility. Biocompatibility testing is mandatory considering that these implants are left in the human body for life.

Several different animal models of PDA are described for evaluating the efficacy and safety of implants for interventional PDA closure. Abrams $^{8}$ dilated the ductus arteriosus in newborn lambs and dogs with additional application of heat or formalin. Angioplasty of the ductus arteriosus in an experimental setting was first described by Lund.

We employed a PDA model in which persistence of the ductus arteriosus was achieved by repetitive angioplasty without additional application of thermal energy, fixatives, or any therapeutic agent locally or systemically.

After device closure of the PDA, the time pattern of formation of a cellular monolayer on the aortic and pulmonary surface of the implants was equal for all devices. The first step in the coverage of the implants was the formation of a fibrin net, with inclusion of thrombocytes and erythrocytes on the surface of the biomaterial exposed to blood. This was followed by the cells spreading over the fibrin net. A confluent monolayer of the cells could be demonstrated in all specimens with implantation times of 32 days or longer. Immunohistochemical staining identified these superficial cells as endothelial cells.

The initial mechanism of occlusion of the ductus arteriosus appeared to be thrombus formation around the biomaterial in all types of implant. Cellular organisation of the thrombotic material was completed within six weeks after implantation of a polyvinylalcohol plug or a nickel/titanium coil, and was demonstrated only six months after application of the stainless steel coil.

Polyvinylalcohol material has not shown any inhibition of cell proliferation in vivo. ${ }^{10}$ This has been explained by its low toxicity and the hydrophilic character of the hydroxyl groups of the polyvinylalcohol.

The difference in ingrowth of the two metal implants may be caused by different binding conditions of the metallic ions. For the stainless steel implants the nickel ions dissolve to a large extent, whereas with the nickel/titanium implants formation of an almost inert superficial film of titanium oxide on the interface with surrounding compartments prevents dissolution of the nickel ions. ${ }^{11}$

Thrombus formation raises the possibility of recanalisation. ${ }^{12}$ Thus rapid cellular organisation of thrombus material after implantation is desirable to avoid recanalisation. Taking this into account our study suggests that nickel/ titanium might be preferable to stainless steel as implant material.

Examination of the cells after organisation of the thrombotic material in the central portion of the ductus arteriosus showed characteristics of fibromuscular cells. Such fibromuscular cells are also found with remodelling of arteries after angioplasty or stent implantation. In contrast to the latter cell proliferation is intended after implantation and substantially supports the closure of a PDA.

Apart from a mild inflammatory reaction probably caused by thrombus formation, few inflammatory infiltrates were detected in our series. Foreign body reaction directed against coil material was seen in one lamb from the stainless steel coil group, and in two lambs from the nickel/titanium coil group, and thus appears to be an individual response.

\section{Conclusions}

Our study shows that thrombus formation is the primary mechanism of occlusion of the ductus arteriosus after implantation of a device for closure. The time pattern of replacement of the thrombus material by cells depends on the material of the device, whereas formation of a cellular layer on the aortic and pulmonary surfaces of the implants occurs in a time pattern independent of the material involved. Only single cases showed localised inflammatory infiltrates independent of material and time.

This work was supported in part by grant $01 \mathrm{KS} \mathrm{9503/9} \mathrm{from}$ the German Ministry of Research and Technology, Bonn, Germany. The authors thank L Muys and S Säuberlich for technical assistance, and C Gurr for editorial assistance. Thanks also are due to the departments of electron microscopy and experimental animal research at the medical faculty of the Aachen University of Technology, for their technical support and exper-

1 Porstmann W, Wierny L, Warnke H. Closure of ductus arteriosus persistens without thoracotomy. Radiol Diagn Berl 1968;9:168-9.

2 Rashkind WJ, Cuaso CC. Transcatheter closure of patent ductus arteriosus. Successful use in a 3.5 kilogram infant Pediatr Cardiol 1979;1:3-7.

3 Rao PS, Wilson AD, Sideris EB, Chopra PS. Transcatheter closure of patent ductus arteriosus with buttoned device: first successful clinical application in a child. Am Heart $\mathcal{f}$ 1991;121:1799-802

4 Rigby ML. Closure of the arterial duct: past, present, and future [editorial]. Heart 1996;76:461-2.

5 Pauperio HM, Redington AN, Rigby ML. Closing the patent ductus arterial duct-plugs, umbrellas and coils. Cardiology in the Young 1996;6:252-4.

6 Grabitz RG, Schräder R, Sigler M, et al. Retrievable patent ductus arteriosus plug for interventional, transvenous occlusion of the patent ductus arteriosus. Evaluation in lambs and preliminary clinical results. Invest Radiol 1997;32:523-8.

7 Grabitz RG, Freudenthal F, Sigler M, et al. Double-helix coil for occlusion of large patent ductus arteriosus: evaluation in a chronic lamb model. If Am Coll Cardiol 1998;31:677-83.

8 Abrams SE, Walsh KP, Diamond MJ, et al. Radiofrequency thermal angioplasty maintains arterial duct patency. An experimental study. Circulation 1994;90:442-8.

9 Lund G, Cragg A, Rysavy J, et al. Patency of the ductus arteriosus after balloon dilatation: an experimental study. Circulation 1983;68:621-7.

10 Burczak K, Gamian E, Kochman A. Long-term in vivo performance and biocompatibility of poly(vinyl alcohol) hydrogel macrocapsules for hybrid-type artificial pancreas. Biomaterials 1996;17:2351-6.

11 Rondelli G. Corrosion resistance tests on NiTi shape memory alloy. Biomaterials 1996;17:2003-8.

12 Kumar V. Thrombosis. In: Cotran RS, Kumar V, Collins T, eds. Pathologic basis of disease. 6th ed. Philadelphia: Saunders, 1999:124-38. 